\title{
米丘林生物学对于我國馬鈴莕 退化問題的啓示.
}

\author{
林 傳 光
}

（北京警業大学、中國科学院㙋菌及植病研究室）

\section{一 引霄}

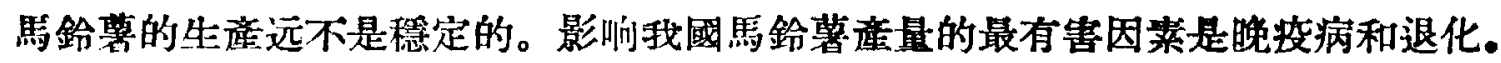
晚疫病是多雨年仍的毁珹性病害，受害较重的主要是北部早已建立起來的馬鈴薯度区。

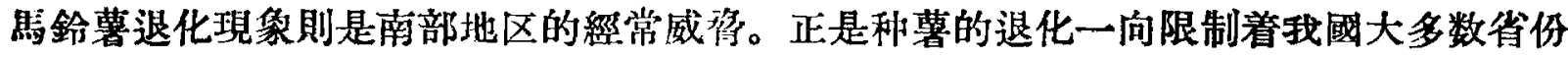

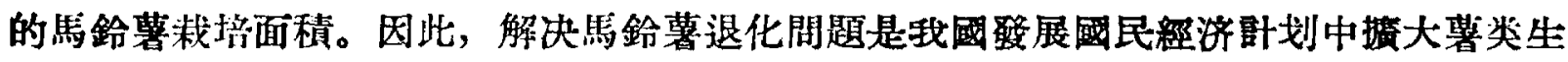
任务上的关键。

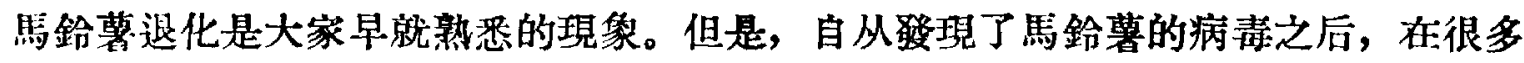
片陑的植物将理学家和農学家的心目中, 好像退化現象变成不存在的了。这种單紨病毒 观点長期阻碍着解决問題的途徑。

与此相反， H.B.米厉林不僅承認植物界中品和退化現像的存在，而且.正确地指出 了生念因装变为不適合植物本性的要求时促使它的退化的作用。米正林的关于品利这化 的兴:說，一方面充实了有机体与环境辯証統一的基本原理的內容，另一方面給李林科院

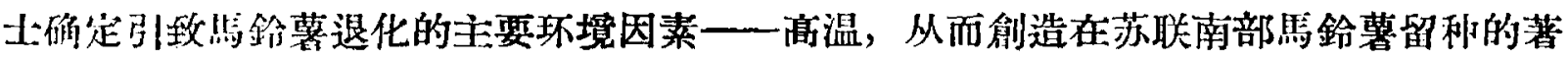
名方法一一播法开辟了道路。米丘林和李森科的这些光輝成䘛便是我們現在研究我國 馬鈴薯退化间題的直接指南。

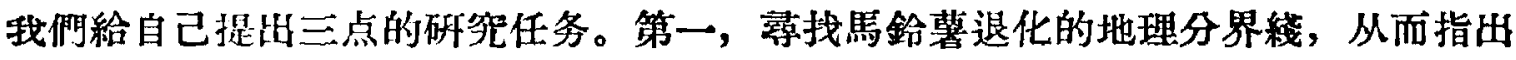
最合理的調利方法。第二，研究在騎鉿暮退化地区防止退化的方法，以达到就地留利的 目的。第三，根据自然界所呈現的事实，通过進一步的試驗來分析退化現像的有关因

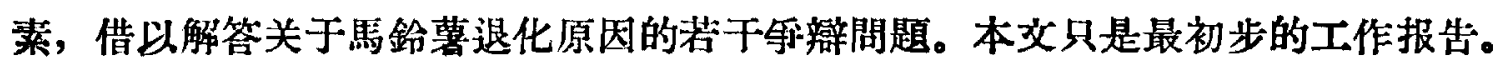

\section{二 地区一候与馬舲学退化的关柔}

从馬鈴著的栽培歷史上，至少在我國，首先应当肯定馬鈴著在某些地区的一定范总

- 本女所引用的全部試驗資料及部分的調查資料是在黄河、田波、張秀華諸同志协助下獲得的，在工作進行

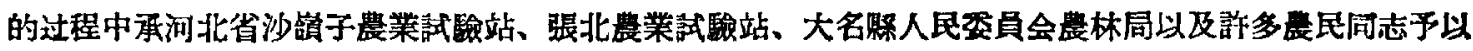
种种的便利, 特此志謝。

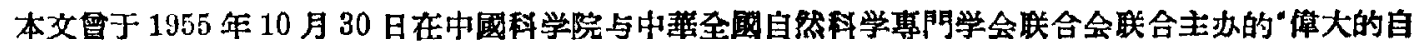

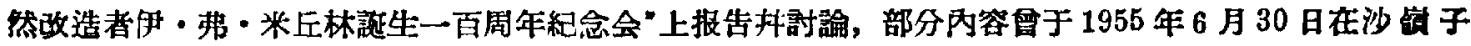

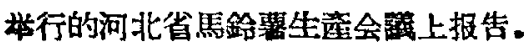

4 月号

科学通报

- 23 . 
队不發生退化，因为一般栽培品种在这些地区都是栽培了多年而仍然保持眉高差能力的。

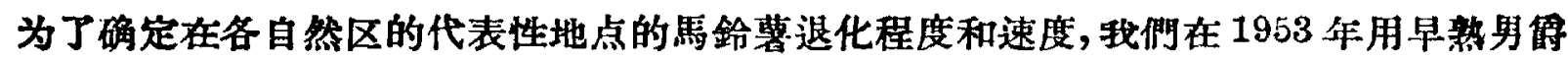
品种的同一批种薯, 分为三部分分別在河北省范園队的北京, 沙湎子(位于浱家口南 15 公里）和商都（位于張北粕西北約 150 公里）种植，准备以后每年艾換各地所䦽的种暮， 从第二年起把商都这一地点改为張北。1954 年和 1955 年航得的造量結果列于表 1 和 表 2 .

表 1 馬鈴蓄調种試驗的第二年的精果

\begin{tabular}{|c|c|c|c|c|c|c|c|c|}
\hline \multirow{2}{*}{\multicolumn{2}{|c|}{ 1953年的种植地点 }} & \multicolumn{7}{|c|}{ 1954年在各地点辣培的量（斤/能） } \\
\hline & & 北 & 京 & 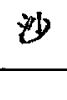 & \multirow{2}{*}{$\frac{\text { 嶺 }}{1969}$} & \multirow[t]{2}{*}{ 子 } & \multirow[t]{2}{*}{ 鲰 } & \multirow[t]{2}{*}{ 北 } \\
\hline 北 & 京 & & & & & & & \\
\hline 沙 & 子 & & & & 3501 & & & \\
\hline 謪 & 都 & & & & 4880 & & & \\
\hline
\end{tabular}

表 2 馬鈴薯調种試驗的第三年的䊅果

\begin{tabular}{|c|c|c|c|c|c|}
\hline \multicolumn{2}{|c|}{ 种薯的种植地点 } & \multicolumn{4}{|c|}{ 1955年在各地点载培的幥量（斤能） } \\
\hline 1953年 & 1954年 & 北 & 沙 & 嶺 子 & 㖘 \\
\hline \multirow[b]{2}{*}{ 北 索 } & 北京 & 1210 & & 1660 & 998 \\
\hline & 沙㟧子 & 1510 & & 1910 & 1244 \\
\hline & 张 北 & 1270 & & 2340 & 1201 \\
\hline & 北 & 1920 & & 2061 & 1085 \\
\hline 沙站子 & 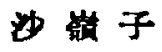 & 1300 & & 2134 & 1111 \\
\hline & 张 & 1960 & & 2993 & 2021 \\
\hline \multirow{3}{*}{ 福 } & 北 & 1980 & & 2620 & 1436 \\
\hline & 溢子 & 2110 & & 2925 & 2144 \\
\hline & 倨 北 & 2900 & & 3858 & 2810 \\
\hline \multicolumn{2}{|c|}{ 开花至收㮃日期 } & $28 / V-8 /$ VII & & $\mathrm{VI}-4 / \mathrm{VI}$ & $5 / V I I-23 / 1$ \\
\hline
\end{tabular}

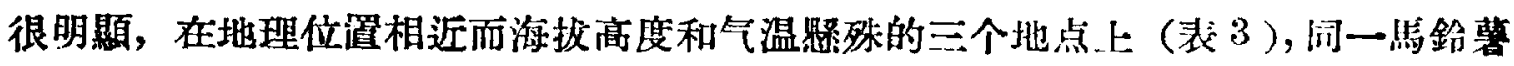
品种的末退化种薯在春季栽培条件下都能达到高額的量。但是, 从表 1 叮以看到, 在 北京栽培过一年的，退化的程度就使第二年的量降低到 $1 / 3$ 左右; 沙领子的，降低到

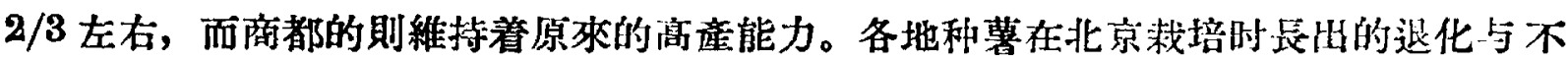

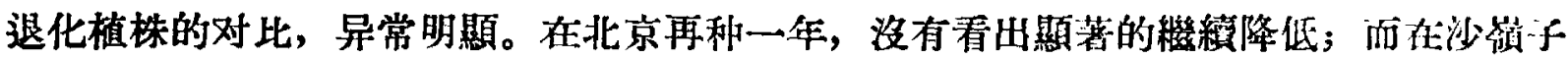
种过兩年的, 第三年的座量又降低了 $1 / 3$, 达到与在北京連科雨年的种莠相近的生 水

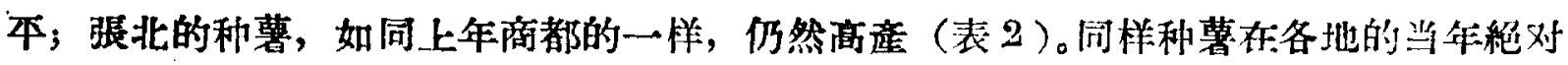
量, 主要由于不同的土壤和载培管理条件, 有相当大的盖别; 但是退化与不退化种薯 之間在各地所表現的產量差异的比例是一致的。

我們可以初步做出結論, 接照張北椆的海拔和温度标准可以划出華北区馬鈴薯退化 的界挠。在張北䅫及其北的地区馬鉿著基本上可以保持优良的种用品筫。 
表 3 調种試驗中各地点的地理位置、海找常度

及春播馬鈴薯生長期的溫庭情况

\begin{tabular}{|c|c|c|c|c|c|}
\hline \multicolumn{2}{|c|}{ 地 } & 点 & 張 & 娠 家 口 & 北 \\
\hline \multicolumn{2}{|c|}{ 北 } & 緯 & $41^{\circ} 05^{\prime}$ & $40^{\circ} 50^{\prime}$ & $39^{\circ} 54^{\prime}$ \\
\hline \multicolumn{2}{|c|}{ 东 } & 䋑 & $114^{\circ} 49^{\prime}$ & $114^{\circ} 55^{\prime}$ & $116^{\circ} 28^{\prime}$ \\
\hline 鬲 & \multicolumn{2}{|c|}{ 度(米) } & 1,450 & 776 & ธ1 \\
\hline$\eta$ & $\begin{array}{l}\text { 平 } \\
\text { 均 }\end{array}$ & $\begin{array}{l}5 \text { 月 } \\
6 \text { 月 } \\
7 \text { 月 } \\
8 \text { 月 }\end{array}$ & $\begin{array}{l}10.0 \\
16.4 \\
18.0 \\
17.7\end{array}$ & $\begin{array}{l}17.1 \\
21.9 \\
23.9 \\
22.1\end{array}$ & $\begin{array}{l}20.1 \\
24.4 \\
26.1 \\
24.9\end{array}$ \\
\hline \multirow{2}{*}{$\begin{array}{l}\text { 括 } \\
\text { 昏 } \\
\text { 度 }\end{array}$} & 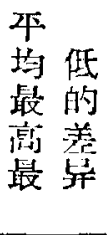 & $\begin{array}{l}5 \text { 月 } \\
6 \text { 月 } \\
7 \text { 月 } \\
8 \text { 月 }\end{array}$ & $\begin{array}{l}13.9 \\
13.1 \\
11.3 \\
11.5\end{array}$ & $\begin{array}{l}14.5 \\
13.8 \\
11.3 \\
11.6\end{array}$ & $\begin{array}{r}13.6 \\
12.6 \\
10.2 \\
9.8\end{array}$ \\
\hline & $\begin{array}{l}\text { 檽 } \\
\text { 端 } \\
\text { 高 }\end{array}$ & $\begin{array}{l}5 \text { 月 } \\
6 \text { 月 } \\
7 \text { 月 } \\
8 \text { 月 }\end{array}$ & $\begin{array}{l}28.0 \\
30.5 \\
35.5 \\
29.1\end{array}$ & $\begin{array}{l}35.1 \\
38.2 \\
38.4 \\
35.7\end{array}$ & $\begin{array}{l}37.4 \\
41.6 \\
39.9 \\
37.5\end{array}$ \\
\hline
\end{tabular}

目前我們还沒有覌察到已退化的种暮在張北溨培后的复壯現象。

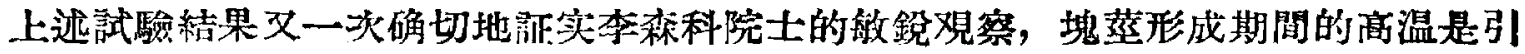
致熙鉿薯退化的主要因素。这里我們特別强調土壤浽度和温差的意义。在我國北部游扱

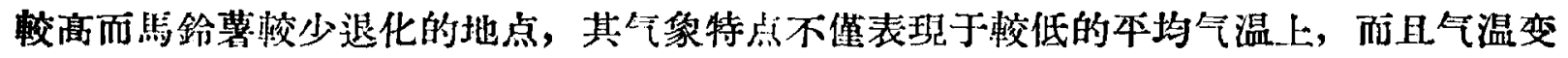
动的幅度较筧（表 3 ）。这就可能使植株下洎土壤耕厤形成种薯的地方在白天炎热的时間 保持着远低于气温的温度。如下面所要證明的，植株地上部和地下部的这种温度差別，

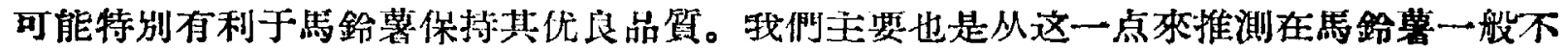
退化的地方琴个別退化植株，和在一般退化的地方父有个別不退化植株的原因。可以 钤想, 在同一自然区队，甚至于在同一地的田地上，土壤温度可以丒于小范圆丽的植株

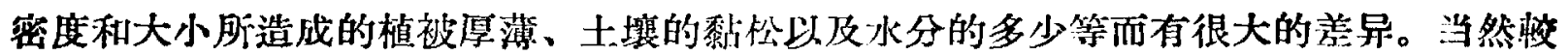
接近于土面的塊蕉也会受到较高温度的影响。这样，土壤温度的作用就㙷得夜为笑出。

\section{三 土㜔和载培条件与馬给鲁退化的关系}

在气温䡆的地区，应用李森科所提出的夏播方法，無疑在很大的程度上可以克服 馬鉿敬的退化。阙題在于，在我國的目前条件下，种著的低温拧藏有实际的困难。在多 数地区，由于春季的气温滈、地下水位鄗等等的情况，除非有冷藏的設备，难免馬鈴惑 到夏季播种的適期之前就發出長芽而完全失去其和用价值。

因此，如果要解决我國各地的就地留种問題，就有必要唠找切实可行的其他类似方 


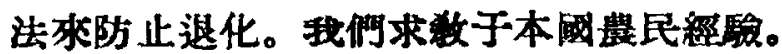

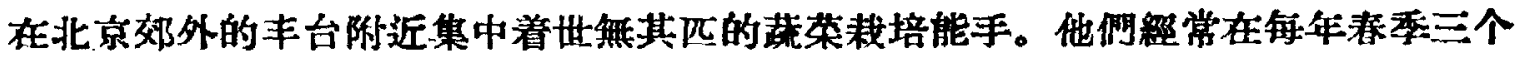

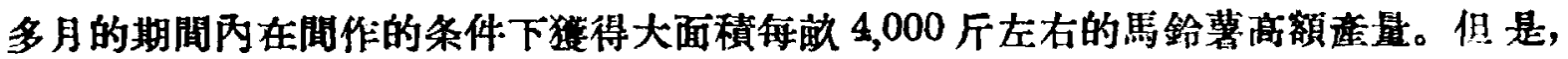
他們却需要从外地瞵运种薯。早先一般从張家口獾得北部的种著。近年來随天津斉区的

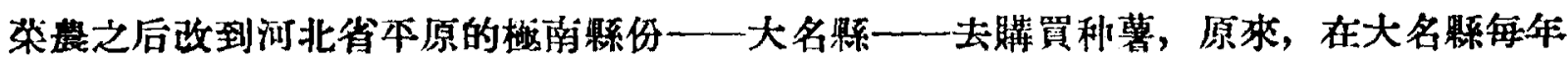
雨季連縝栽培了一个早繁紅皮品种（現在我們称之为大名紅）已达四十年而仍然保持着 該品种的优良賈量。如表 4 所示，大名的气温慜著高于北京和天津的气温。最有趣的是，

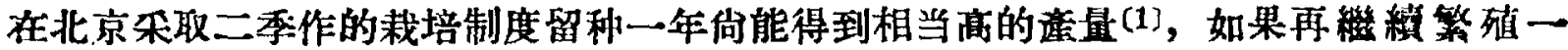
年，种薯退化的程度就使量落到释济的标准之下了。

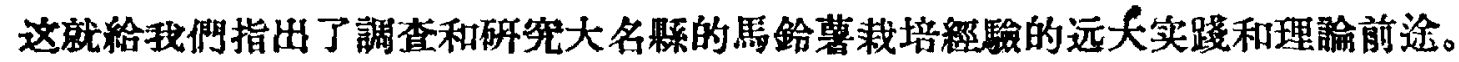

表 4 北京、天津和大名的秋播馬鈴薯生長期間的温度情况

\begin{tabular}{|c|c|c|c|c|c|c|c|c|c|c|}
\hline \multirow{3}{*}{ 地 } & \multirow{3}{*}{ 点 } & \multirow{3}{*}{ 北緯 } & \multicolumn{5}{|c|}{ 气 } & \multicolumn{3}{|l|}{ 温 } \\
\hline & & & \multicolumn{2}{|l|}{ 平 } & \multirow{2}{*}{$\frac{\text { 均 }}{10 \text { 月 }}$} & \multirow{2}{*}{ 最 } & \multirow{2}{*}{$\frac{\text { 高 }}{8 \text { 月9月 } 10 \text { 月 }}$} & \multicolumn{2}{|c|}{ 最 } & \multirow{2}{*}{$\frac{\text { 低 }}{10 \text { 月 }}$} \\
\hline & & & 8 月 & 9 月 & & & & 8 月 & 9 月 & \\
\hline \multirow{2}{*}{ 北 } & \multirow{2}{*}{ 京 } & \multirow{2}{*}{$39^{\circ} 54^{\prime}$} & \multirow{2}{*}{24.9} & \multirow{2}{*}{20.1} & \multirow{2}{*}{12.7} & 本均 & 30.426 .620 .5 & 20.6 & 14.6 & 6.6 \\
\hline & & & & & & 極端 & $37.5 \quad 34.3 \quad 30.5$ & 12.2 & 1.6 & -2.9 \\
\hline \multirow{2}{*}{ 天 } & \multirow{2}{*}{ 津 } & \multirow{2}{*}{$39^{\circ} 08^{\prime}$} & \multirow{2}{*}{262} & \multirow{2}{*}{22.0} & \multirow{2}{*}{14.8} & 平均 & 30.727 .220 .6 & 21.8 & 16.7 & 9.1 \\
\hline & & & & & & 棰端 & 37.134 .829 .2 & 13.9 & 8.2 & -1.1 \\
\hline \multirow[t]{2}{*}{ 大 } & \multirow{2}{*}{ 名 } & \multirow{2}{*}{$36^{\circ} 19^{\prime}$} & \multirow{2}{*}{25.9} & \multirow{2}{*}{22.1} & \multirow{2}{*}{15.4} & 平均 & $-\quad-$ & - & $\rightarrow$ & - \\
\hline & & & & & & 極端 & $38.0 \quad 34.0 \quad 29.4$ & 14.0 & 6.0 & 0.0 \\
\hline
\end{tabular}

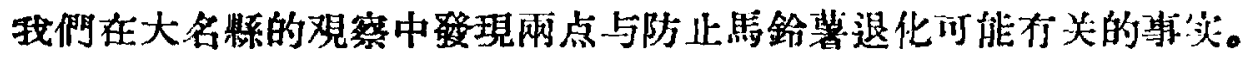

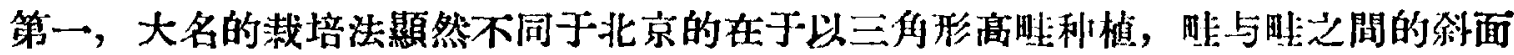

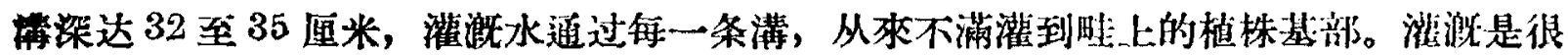

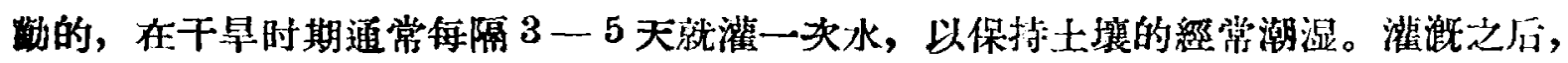

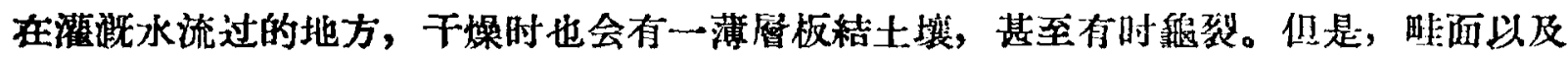
內部的土壤則是释常疏松的, 如猿那示。

这种栽培法，一方面保証土壤中的大量合水，另一方面又保証了充分的空气供給。 这一切都給土壤中保持较低的温度創造特別优越的条件。在 1955 年很炎热的一天，6月 5 日中午至午后 4 时, 当稙株中㻺叶的叶背温度达到 $30-36^{\circ} \mathrm{C}$ 的时候，畦面下 10 景米

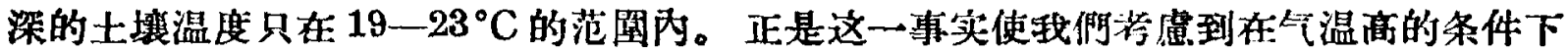
保持土壤低温的重要性和可能性。

目前大名的馬鉿暮栈植距离还是太筧。一般行距 60 厘米，株距 30-40 厘米。我們 想, 如果稍为加賞畴面, 实行每睢双行密植, 通过植被的加厚, 可能会更有效地保持土 壤的纸温。当然，落植也同时是一般的㘿措施。

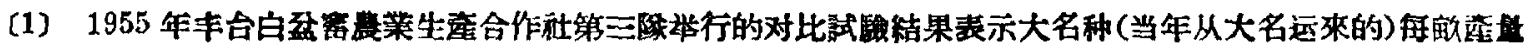

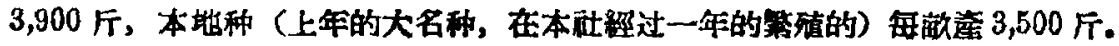


第二，大多䅫栽培些鈴著的士。 壤鹿是河北省著名棉区的所謂“雨合 土”。这是一科晤紅色沙筫壤士，合綎 在几十年的速作条件下玈常保桩着棉

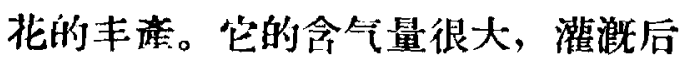
的板結曆下面具有类似团粒的結構。 这种土燷特性, 柾与上述栽培法相適 应，保持着对留鈴薯供給空气和水你 的理想情况，也避免土堆受 H間高温

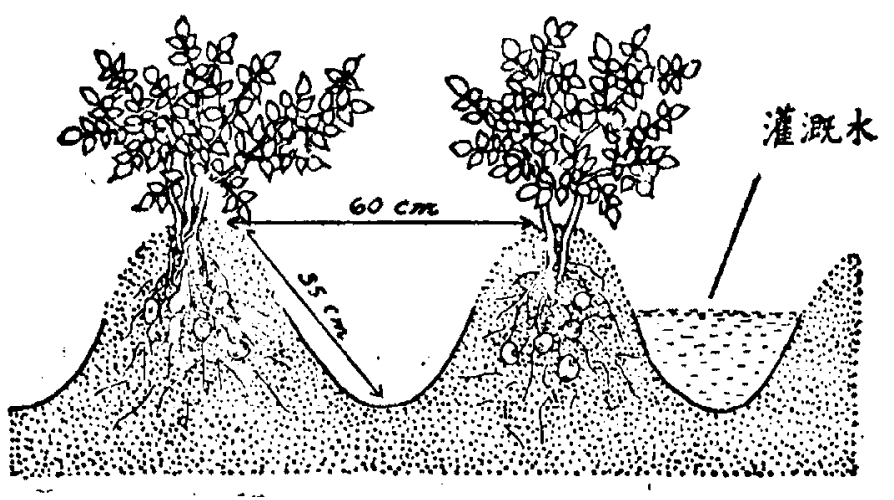

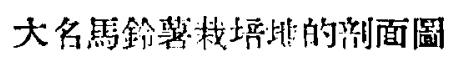
影响而有鲁剧的变动。此外，“网合士”可能还具有其他优良特性。

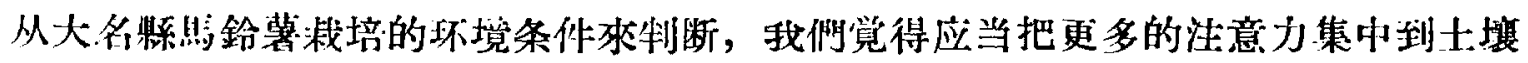

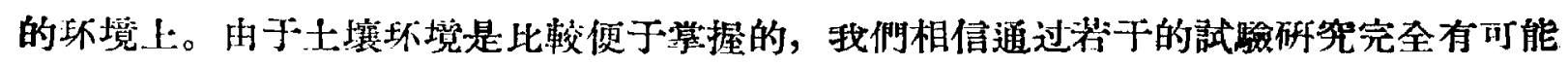
在不久的将來在很多地区防止些鈴著的退化，解决就地留种阙題。

在二季作的栽堗制度，上，然論在大名或是在丰台目前都存在着第二季栽培的利势催

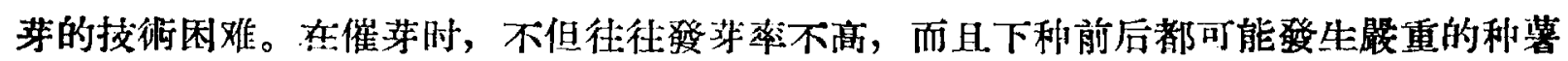
㻺爛現家，因而造成䣄株。

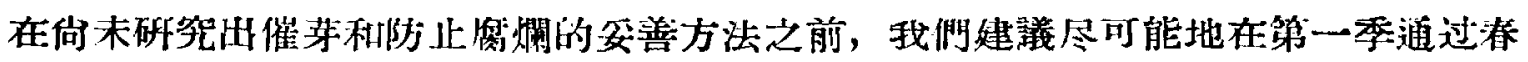
化方法等等提早利许出土期, 借以相应提早成熟期, 在第二季延迟播种期。这样就讧以

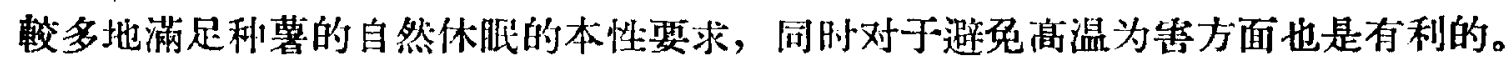

\section{四关于馬鈴爱退化与病毒的关系的假定}

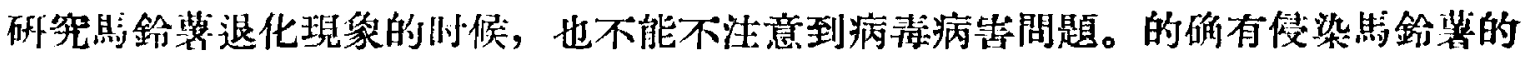

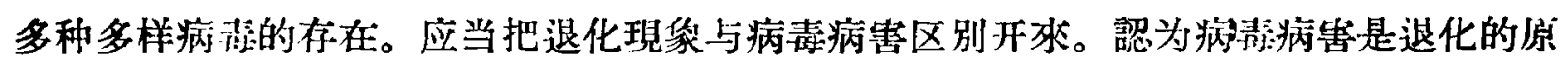

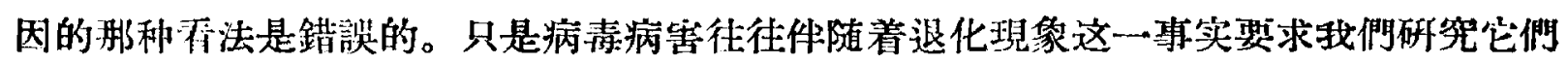

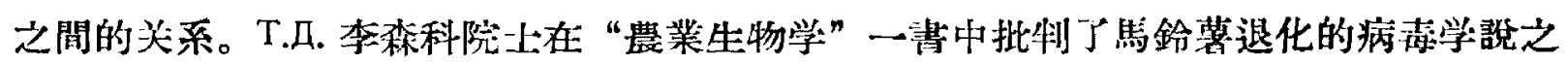

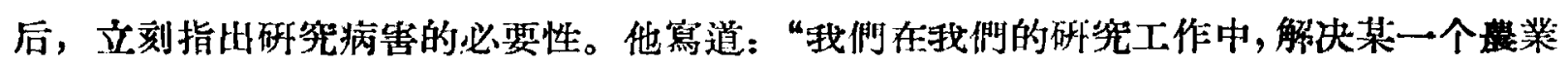
生物学䦓題的咕候，照例从分析有机体与其周圍外界环境的相互关系开始。在做这种分 析的时候，当然也不应該忽略各种病害以及这些病害的發展条作。”

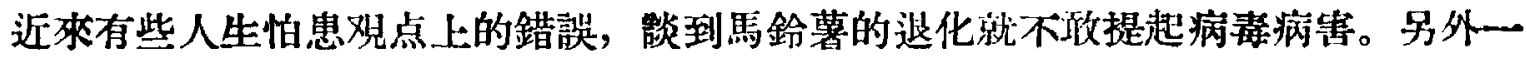
些人硬把退化和病毒病管成好像它們之間是掌無关系的。还有一些人断章取义地引詐李

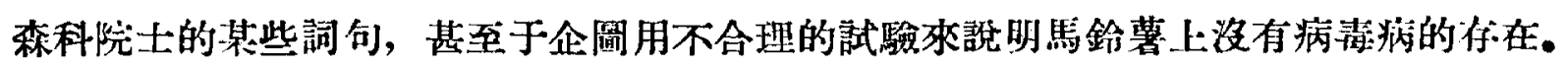
我們認为这类态度都是不正确的, 持且是妨碍科学的。

在前达的調种試驗中所看到的馬鈴著退化的速度和程度应該特別引起植物狱毒学家 的警奇。不能設想商都或張北的种著在北京种植的头一年儿乎全部是新受病潾的侵染。 在我們的各地区的試驗地上扭没有發現昆媒介数量的顯著差別。然而, 在北京所留的 种薯第二年栽培时的确絕大多数的植株都表現出典型的解縮花叶病狀。事实上，我們法 意到，在不退化地区所形成的和要也常常長出强出而具有輕微解縮花叶病狀的植株來， 这种情况对于造量没有什么影响。以后随着植株的退化, 病毒病害的症狀就变成更加响 
重了。这样, 病襄病害可能又会加速植株的退化。我們想, 在外界环境变为不適宜于用

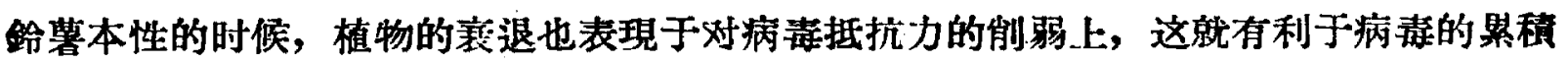
而加强其对于植株的为害。也可能, 不適合于馬鈴暮的外界环境条件, 例如土壤高温, 对于病毒在植物体內的繁殖或移动隶說, 正是適宜的外界环境条件。这就会進一步促進

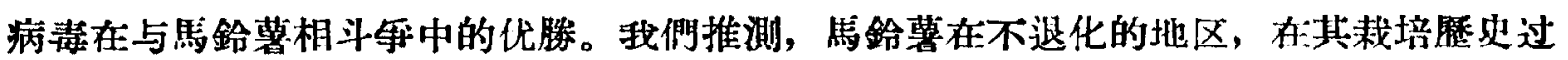
程中, 其群体的大多数都已經或早或晚地受到了病等的侵染, 但是那里的病表只能在很 低的浱度水本上保存着。因此，病毒只能作为駼鈴著的有害环境条件之一㶱加以考虑， 其为害性肯定远比不上土壤高温。上述的种种假定, 暂时究竟还是假定, 但是将來都是 可以一步一步地通过嚴格控制的实驗來加以检查的。

\section{五 建䄔}

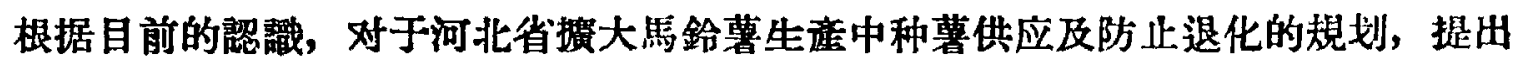
如下的建議：在馬鈴暮灾害方面, 河北省可以分为三段的地帶。張北夥以北沒有退化間

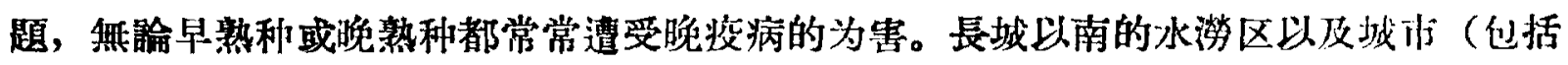

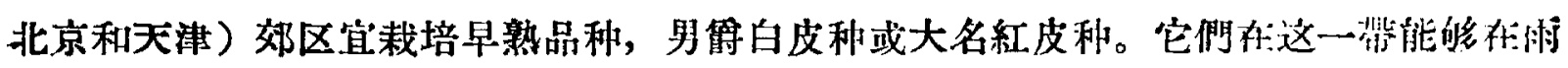
季之前成熟, 因此没有發生晚疫病的危險, 但是退化閒題格外嚴重。在長城以北至张家 口的一需, 晚疫病和退化都会發生, 在晚㠇种上晚疫病較重, 而在早熟种上退化較重。

关于晚疫病的預測和防治問題已另有报告 (見植物病理学报第一管第一期, 1955年-3 北京豊業大学学报第一必第二期, 1955 年)。

在長城以北的地区可以通过聍藏柗的改善实行夏播法來防止退化。

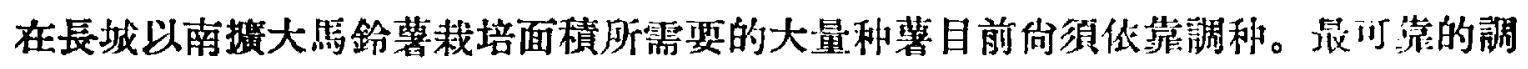
和方法是，在張北或靠近內蒙的沿鉄路綫的地点建立大規模的留种場，主要惟培约得品 利，不僅供应本省还可以供应其他省份的利著需要; 在大名夥及邽副装区的其他適当地点

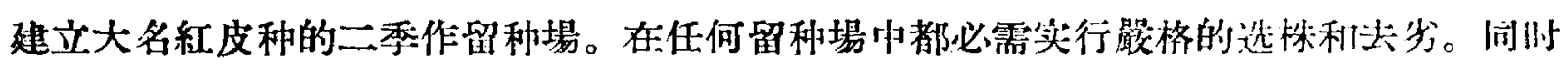

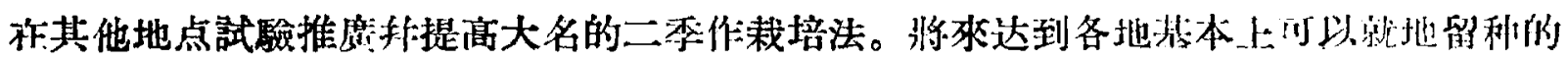

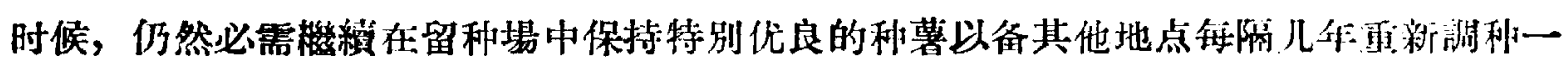

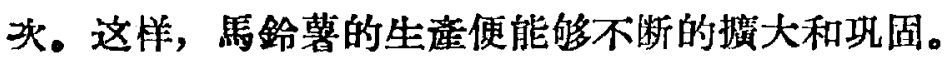

在米丘林誕生百周年紀念会閉幕之后, 我才讀到登载于苏联植物学猚志第 40 無 （1955）第 4 期以“諭馬鈴薯退化的原因”为題的林尼克 (Г. Н. Линик) 渝文。著者指出

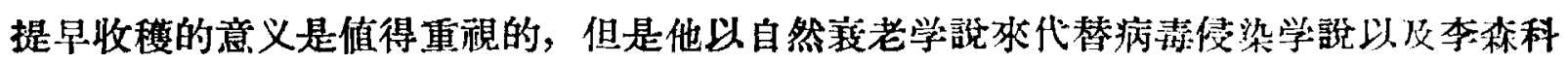
的高温誘学鿁, 則很难命人信服。

著者引証雷日科夫（В. Л. Рюжков） 20 年前的著作中的某些詞句來批判病清侯染

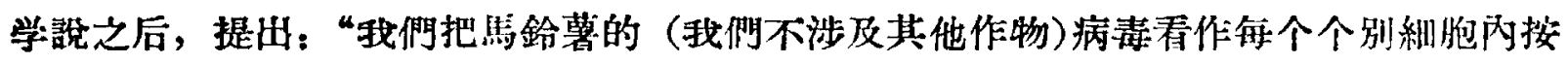

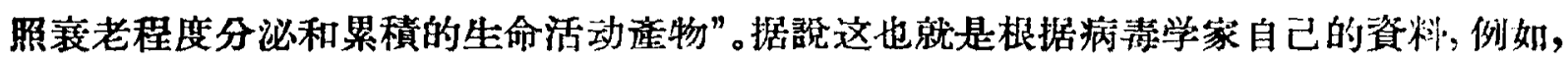
“病毒在植物体內移动的速度每小时等于 0.1-0.2 厘米（雷日科夫，1930）”，“这些数字 是与植物的生長速度相符合的”。其实, 大家知道病毒的移动, 虽然在薄壁組繊叫是䌅慢

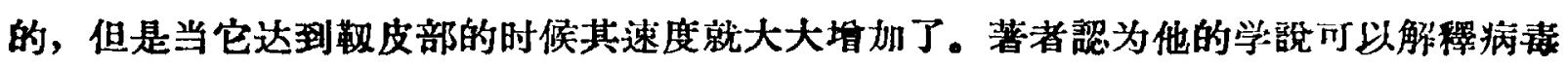


学家所不明白的事情。实际上，对于 20 年前不明白的許多事情, 病毒学家早已明白了。

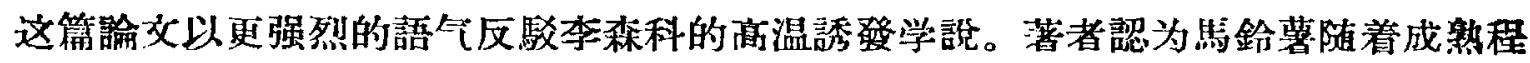
度而必然退化，因此退化現像与生态因素無关而随时到处發生，在北方退化较慢是因为

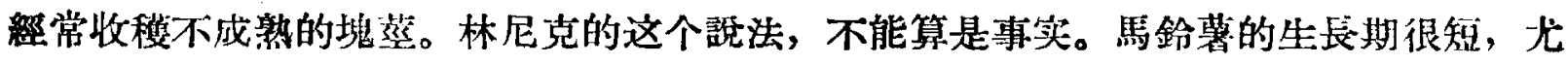
其是早熟品种。在我們的試羷中，馬鈴薯在不退化的地区也是䌌常等到完全成熟而植株 完全枮干之后才收穫的。至于-个别植株的退化，我們已經从温度的覌点做丁另外的解

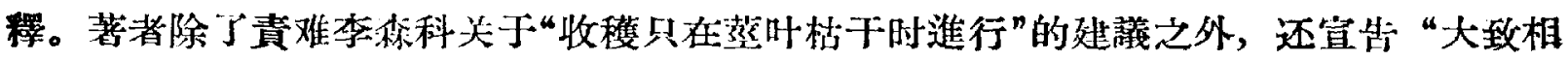
同的夏播法在文献中早已知道了”，“在实踐中，这种方法在德湜泊三何洲自古以來就应

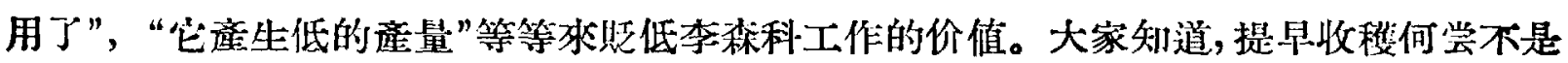

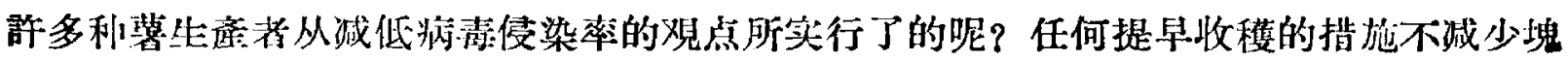

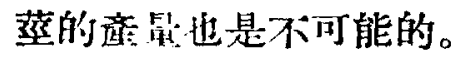

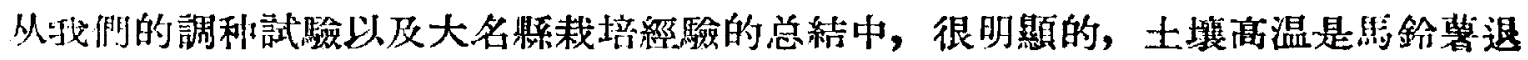
化的决定性因素。叮以肯定，土瓖高温是不利于照鈴薯特性的發展的。我們特別洁意的

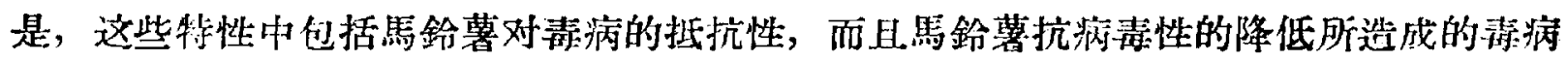

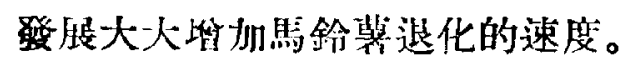

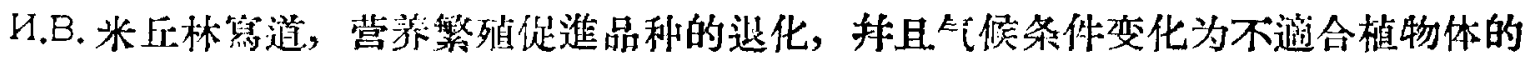

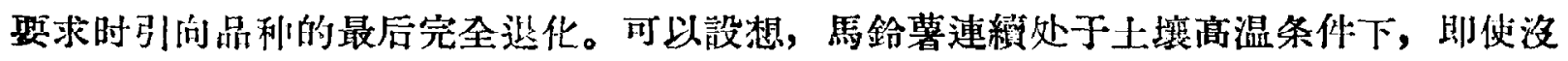
有涴表的存在最后也必然会完全退化。

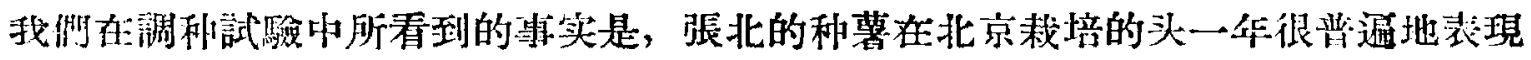

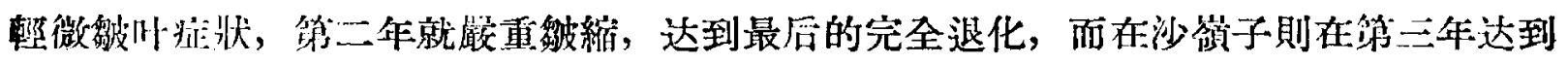
相同的程度（这利情况不能昌昆虫的数量相联系）。最近在我們的实驗室中, 把利慕的幼

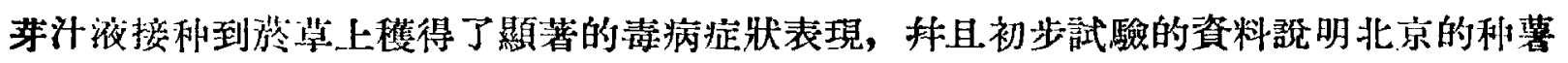

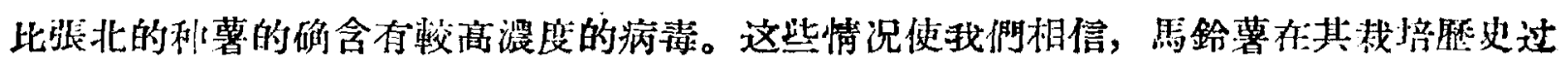

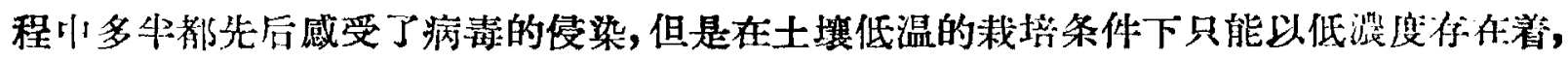

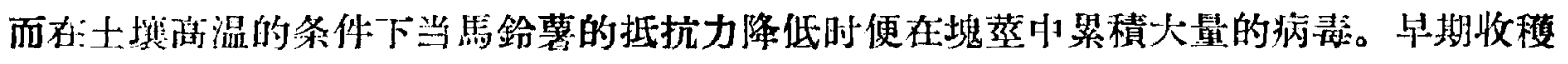

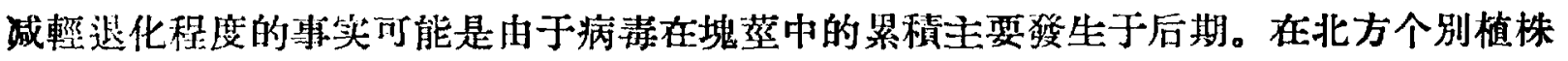

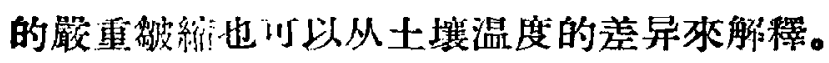

会發生这样的問題: 是否我們刃把馬鈴暮退化問題回到病毒学群上去呢? 的确, 我 們对于病浗在漹鈴薯退化上的作用比李森科院上做较多的佔計。然而, 退化指的是駩鉿 薯本身特性的变化。在病毒和高温同是駩鈴薯的不良外界条件之間, 影然高温是主要的。

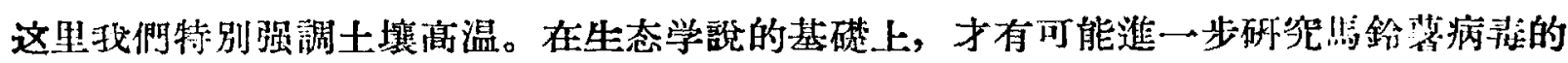
作用。我們对于林尼克論交的意見也就在于它采納了一部分的事实, 而抹攵了許多其他 事实。

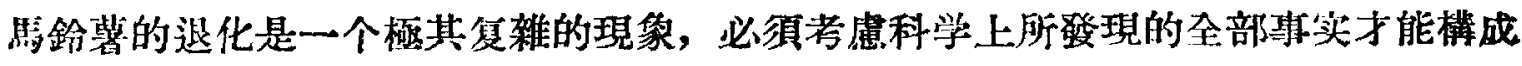
正确的見解，在实踐中，更必須接照具体条件的可能性梁取一切有利指施。 